DOSSIÊ TEMÁTICO: Formação Docente, Práticas Pedagógicas e Relações Raciais e de Gênero

dO https://doi.org/10.22481/praxisedu.v16i39.6360

\title{
OS DESAFIOS EPISTEMOLÓGICOS E PRÁTICOS PARA O ENFRENTAMENTO DO RACISMO NO CONTEXTO ESCOLAR
}

\author{
THE EPISTEMOLOGICAL CHALLENGES AND PRACTICAL FOR RACISM COPING \\ IN THE SCHOOL
}

\section{LOS DESAFÍOS EPISTEMOLÓGICOS Y PRÁCTICOS PARA EL ENFRENTAMIENTO DEL RACISMO EN EL CONTEXTO ESCOLAR}

\author{
Eugenia Portela Siqueira Marques \\ Universidade Federal do Mato Grosso do Sul - Brasil \\ Wilker Solidade da Silva \\ Universidade Federal do Paraná - Brasil
}

\begin{abstract}
Resumo: Este artigo apresenta os procedimentos metodológicos e os resultados da pesquisa "Políticas Públicas para a Educação das Relações Étnico-Raciais: as Possibilidades Abertas pela Lei $\mathrm{N}^{\circ}$ 10.639/03 nas escolas públicas estaduais de Mato Grosso do Sul”. A investigação foi realizada em parceria com o Núcleo de Diversidade da Secretaria de Estado de Educação e o Núcleo de Estudos Afro-brasileiros da Universidade Federal da Grande Dourados, e apresenta os desafios epistemológicos e práticos para a decolonização curricular e o enfrentamento ao racismo no âmbito escolar. O processo de implementação das Diretrizes Curriculares Nacionais para a educação das relações étnico-raciais e para o ensino da Histórica e cultura afro-brasileira e africana desafia a gestão escolar e aos docentes a romperem com o mito da democracia racial e com o silenciamento ou ocultação sobre o racismo e discriminação racial que ainda subalternizam e inferiorizam a diferença negra. A pesquisa utilizou análise documental, entrevistas, questionário e observações. Os resultados da pesquisa apontaram que essas legislações requerem outros paradigmas para se pensar a diferença étnico-racial e possibilita o rompimento da visão homogeneizadora e hegemônica de educação.
\end{abstract}

Palavras chave: Educação; Lei nº 10.639/2003; Relações Étnico-raciais; Decolonialidade.

Abstract: This article presents the methodological procedures and the results of the survey "Public Policies for the Education of Ethnic-racial Relations: the Possibilities Open by Law n 10.639/03 in the state public schools of Mato Grosso do Sul". The research was conducted in partnership with the Center of Diversity of the State Department of Education and the Nucleus of Afro-Brazilian Studies of the Universidade Federal da Grande Dourados, and presents the epistemological and practical challenges for curricular decolonization and tackling racism in the school environment. The process of implementing the National Curriculum Guidelines for the Education of Ethnic-racial Relations and for the Teaching of the History and Afro-CultureBrazilian and African challenges school management and teachers to break with the myth of racial democracy and the silencing or concealment about racism and racial discrimination that still underestimate and inferiorize the black difference. The research used documentary analysis, interviews, questionnaire and observations. The results of the research 
pointed out that these legislations require other paradigms to think about ethnic-racial difference and allow the break from the homogenizing and hegemonic vision of education.

Keywords: Education; Law 10.639/2003; Ethnic-racial relations; Decoloniality.

Resumen: Este artículo presenta los procedimientos metodológicos y los resultados de la investigación "Políticas Públicas para la Educación de las Relaciones étnico-raciales: las Posibilidades Abiertas por la Ley $\mathrm{N}^{\circ} 10.639 / 03$ en las escuelas públicas estatales de Mato Grosso do Sul". La investigación fue realizada en colaboración con el Núcleo de Diversidad de la Secretaría de Estado de Educación y el Núcleo de Estudios Afro-brasileños de la Universidade Federal da Grande Dourados, y presenta los desafíos epistemológicos y prácticos para la decolonización curricular y el enfrentamiento al racismo en el ámbito escolar. El proceso de implementación de las Directrices curriculares Nacionales para la educación de las relaciones étnico-raciales y para la enseñanza de la Histórica y cultura afro-brasileña y africana desafía a la gestión escolar y a los docentes a romper con el mito de la democracia racial y con el silenciamiento u ocultación sobre el racismo y discriminación racial que aún subalternizan e inferiorizan la diferencia negra. La encuesta utilizó análisis documental, entrevistas, cuestionario y observaciones. Los resultados de la investigación señalaron que esas legislaciones requieren otros paradigmas para pensar la diferencia étnico-racial y posibilita el rompimiento de la visión homogéneneneizadora y hegemónica de educación.

Palabras clave: Educación; Ley nº 10.639/2003; Relaciones étnico-raciales; Decolonialidad.

\section{Introdução}

O artigo expõe os resultados finais de pesquisa realizada em escolas públicas estaduais de Mato Grosso do Sul sobre os desafios epistemológicos para a implementação das Diretrizes Curriculares Nacionais para a educação das relações étnico-raciais e para o ensino da Histórica e cultura afro-brasileira e africana. Apresenta pressupostos, perspectivas e a urgência para a adoção de práticas pedagógicas e ações efetivas que coíbam a prática de racismo e discriminação de crianças negras no espaço escolar.

A Lei $n^{\circ} 10.639 / 2003$ e, posteriormente, a Lei $n^{\circ} 11.645 / 2008$, que dá a mesma instrução quanto à temática indígena, são instrumentos de orientação para o combate à discriminação racial e também no sentido de que identificam as potencialidades da escola para a formação de cidadãos e a precípua tarefa de valorização das matrizes culturais que fizeram do Brasil o país plural, múltiplo e inigualavelmente rico. Esses preceitos normativos são significativos, na medida em que disciplinaram a Educação das relações étnico-raciais, problematizaram e ressignificaram os currículos monoculturais ao desafiarem à escola a desconstruir o etnocentrismo e a superar as epistemologias racistas, visando à descolonização dos processos pedagógicos. 
Essas legislações exigiram outros paradigmas para se pensar a diferença étnico-racial e colocaram sob rasura o mito da democracia racial no Brasil, que negam a existência da discriminação racial e historicamente reforçaram os processos coloniais e as relações de poder e de saber vigentes nos currículos e nas práticas pedagógicas.

A pesquisa teve por objetivo identificar o processo de implementação das Diretrizes Curriculares Nacionais para a Educação das Relações étnico-raciais e para o Ensino da Histórica e Cultura Afro-brasileira e Africana nas escolas investigadas e as percepções dos docentes e gestores sobre o racismo e a discriminação racial no espaço escolar.

\title{
A decolonialidade curricular e a visibilidade do racismo na escola
}

\begin{abstract}
Olha aqui, vou falar uma coisa para vocês todo dia, todo santo dia, todo dia mesmo, eles mexem com meu cabelo, mexem comigo, e quando eu vou falar pra professora, [ela] não dá atenção, não fala nada, finge que não ouviu",[...] Eu não tô aguentando mais. Todo dia, na escola, na rua, dentro da minha sala de aula, debocham do meu cabelo, não sei por quê [...] o problema é meu, o cabelo é meu. As vezes me batem, me agridem, queria que parassem com isso, entendeu? Não tô aguentando, não dá, não dá... todo dia, muitas vezes são 'um monte' me zoando', '5 marmanjão' do tamanho da minha mãe. Kauan Alvarenga,11 anos. (REDAÇÃO PRAGMATISMO, 2014).
\end{abstract}

Quando se discute o racismo, a interpretação que melhor o traduz é a apresentada por Kabengele Munanga (1996) que o define com uma ideologia que reproduz na consciência coletiva um amplo conjunto de falsos valores e de falsas verdades, e que comprovam as verdades falseadas por meio dos resultados da própria ação. O racismo, assim, atribui inferioridade a uma raça e permite o domínio sobre o grupo, pautado, apenas, em atributos negativos imputados a esse. Ele está baseado em relações de poder, legitimadas pela cultura dominante (MUNANGA, 1996).

A partir dos anos de 2000 identificamos arcabouços jurídicos que podem ser considerados indutores de uma política educacional voltada para a afirmação da diversidade cultural e da concretização de uma Educação das Relações Étnico-Raciais nas escolas. A implementação da Lei no 10.639/2003 que alterou os artigos 26-A e 79-B da Lei 9.394/1996 (Lei de Diretrizes e Bases da Educação Nacional - LDB), a Resolução CNE/CP 01/2004, define Diretrizes Curriculares Nacionais para a Educação das Relações Étnico-Raciais e para o Ensino de História e Cultura Afro-Brasileira e Africana, fundamentada no Parecer CNE/CP 03/2004, e passa a fundamentar o processo de implementação das políticas de ações 
afirmativas na educação brasileira nos seus diferentes níveis, etapas e modalidades educacionais. Representa a concretização de antigos anseios do Movimento Negro, bem como dos intelectuais, educadores e diferentes organismos da sociedade civil que historicamente reivindicam educação democrática, antirracista e a formulação de políticas públicas de promoção da igualdade racial.

As denúncias e demandas do Movimento Negro demonstravam que a ausência de práticas pedagógicas voltadas para a educação das relações étnico-raciais e o silenciamento diante das situações de discriminação que envolvem as crianças negras tornam o ambiente escolar hostil e excludente. A estigmatização e os estereótipos provocam a autorrejeição e a construção de baixa autoestima. A rejeição do corpo, do cabelo dos lábios e demais características físicas é uma fuga, na tentativa de aproximar-se de valores impostos como universais pelo etnocentrismo e, assim livrar-se da rejeição, dominação e inferiorização. A criança negra desde a Educação Infantil e em toda a sua trajetória escolar enfrentará um violento processo e exclusão física, social e simbólico.

A educação básica ainda é profundamente marcada pela desigualdade no quesito da qualidade e é possível constatar que o direito de aprender ainda não está garantido para todas as nossas crianças, adolescentes, jovens e mesmo para os adultos que retornaram aos bancos escolares. Uma das mais importantes marcas dessa desigualdade está expressa no aspecto racial. Estudos realizados no campo das relações raciais e educação explicitam em suas séries históricas que a população afrodescendente está entre aquelas que mais enfrentam cotidianamente as diferentes facetas do preconceito, do racismo e da discriminação que marcam, nem sempre silenciosamente, a sociedade brasileira. $\mathrm{O}$ acesso às séries iniciais do Ensino Fundamental, praticamente universalizado no país, não se concretiza, para negros e negras, nas séries finais da educação básica. Há evidências de que processos discriminatórios operam nos sistemas de ensino, penalizando crianças, adolescentes, jovens e adultos negros, levando-os à evasão e ao fracasso, resultando no reduzido número de negros e negras que chegam ao ensino superior, cerca de $10 \%$ da população universitária do país. (BRASIL, 2004, p.13).

Assim, a partir da interlocução com os dispositivos legais que disciplinam a educação para as relações étnico-raciais e os estudos sobre decolonialidade curricular, essa aqui apreendida como um trabalho que busca desafiar e derrubar as estruturas sociais, políticas e epistêmicas da colonialidade - estruturas até então permanentes - que mantém padrões de poder enraizados na racionalização, no conhecimento eurocêntrico e na inferiorização de alguns seres humanos (WALSH, 2009, p. 12). Com essa percepção, buscamos compreender em que medida as escolas ainda mantêm as práticas de silêncio em relação ao racismo e o 
monoculturalismo que afetam a criança negra colocando-a diante de ideais e estereótipos inatingíveis em relação às suas características físicas, o que interfere na aprendizagem e dificulta a sua afirmação identitária. E, em decorrência de um currículo hegemonicamente eurocêntrico, monocultural e práticas pedagógicas homogêneas e universalizantes que legitimam uma única forma de pensar, ser, saber e viver, na égide da razão modernoocidental-colonial, as experiências produzidas na diferença colonial são ocultadas por não se identificarem com a universalidade abstrata eurocêntrica.

Por isso os espaços educacionais devem promover a eliminação de qualquer forma de preconceito, racismo e discriminação, a fim de que desde pequenas, as crianças compreendam e se envolvam conscientemente em ações que conheçam, e reconheçam a importância dos diferentes grupos étnico-raciais, e também a valorização da história e da cultura afrobrasileira. Visto dessa forma percebemos que:

O acolhimento da criança implica o respeito à sua cultura, corporeidade, estética e presença no mundo [...]. Nessa perspectiva, a dimensão do cuidar e educar deve ser ampliada e incorporada nos processos de formação dos profissionais para os cuidados embasados em valores éticos, nos quais atitudes racistas e preconceituosas não poder ser admitidas. Nessa direção, a observação atenciosa de suas próprias práticas e atitudes podem permitir às educadoras rever suas posturas e readequá-las em dimensões não-racistas [...] Não silenciar diante de atitudes discriminatórias eventualmente observadas é um outro fator importante na construção de práticas democráticas e de cidadania para todos e não só para as crianças. Tais condutas favorecem a consolidação do coletivo de educadores na instituição. (BRASIL, 2006, p. 39).

É importante ressaltar que no ambiente escolar a ausência da desconstrução de todo esse processo pode gerar nas crianças brancas, o sentimento de superioridade ao percebem que possuem as características fenotípicas (cor de olhos, cabelo, boca, nariz) canonizadas e preferidas no currículo, no livro didático e paradidático. Nessa lógica, qualquer desentendimento em sala de aula, no recreio, ou nas aulas de Educação Física, por exemplo, dá margem aos xingamentos e atitudes racistas e, se essas posturas são ignoradas pelos docentes legitimam esse sentimento. Daí a importância de enfatizar que a educação para as relações étnico-raciais deve ser implementada em todas as escolas públicas e privadas, ainda que não tenham crianças negras em sala de aula, pois esse ponto, a nosso ver tem sido interpretado equivocadamente, no sentido de que só é pertinente falar de racismo se tiver alguma criança negra vitimada. Nesse entendimento, Marques (2012, p. 3) ressalta que: 
[...] os estudos sobre os temas decorrentes de História e Cultura Africana e Afro-brasileira não se restringem apenas à população negra, mas diz respeito a todos os brasileiros, cidadãos atuantes numa sociedade plural e multiétnica, visando à construção de uma sociedade democrática e igualitária.

Nesse contexto, os valorosos estudos realizados por Regina Rosemberg (2009), Pahim Pinto (1993), Silva (1995), Kabengele Munanga (1996), Canen (2003), Gomes (2002), Oliveira (2000), Petronilha B. G. e Silva (1997), Siss (2003) e Backes (2006), dentre outros, demonstraram que a escola é seletiva e excludente, uma vez que por muito tempo silenciou-se diante da diferença negra contribuindo de maneira perversa para a sua invisibilidade e inferioridade.

Contudo, destacamos que a implementação da Lei $\mathrm{n}^{\circ}$ 10.639/2003 tencionou a discussão sobre o racismo no ambiente escolar e desafiou a organização do trabalho pedagógico a compreender a cultura afro-brasileira nos espaços coloniais e pós-coloniais que apesar de subalternizada, os saberes da herança africana foi resistente, ao contrapor-se à hegemonia epistêmica colonial e, desse modo, possibilitou uma desobediência epistêmica ${ }^{1}$ para a decolonização dos currículos escolares, por meio do pensamento de fronteira ${ }^{2}$.

Identificamos também que a gestão democrática possui a incumbência para desenvolver com a participação da família, estratégias que favoreçam o desenvolvimento da aprendizagem e formação da criança, e nessa perspectiva, o envolvimento dos pais nas discussões e projetos que possam desconstruir as estruturas racistas que ainda se fazem presentes na sociedade e, consequentemente subverter a lógica da colonialidade e a afirmação das diferenças presentes no espaço escolar. A esse respeito Candau (2002, p.9) observa que:

A instituição escolar está construída sobre a afirmação da igualdade, enfatizando a base cultural comum a que todos os cidadãos e cidadãs deveriam ter acesso e colaborar na sua permanente construção. Articular igualdade e diferença, a base cultural comum e expressões da pluralidade social e cultural, constitui hoje um grande desafio para todos os educadores.

Sob essa ótica, a formação inicial e continuada dos professores, para a decolonização epistêmica, com a visibilidade de outras lógicas deve ser uma das estratégias que possibilitarão a pedagogia decolonial e antirracista capaz de contrapor à geopolítica hegemônica monocultural e monorracial. O estudo sobre as diferenças culturais de cada povo

\footnotetext{
${ }^{1}$ Mignolo propõe o reordenamento da geopolítica do conhecimento para que ocorra o desencadeamento epistêmico a fim de desvencilhar dos conceitos modernos eurocentrados, enraizados nas categorias de conceitos gregos e latinos e nas experiências formadas dessas bases teológicas e seculares (MIGNOLO, 2008).

${ }^{2}$ Expressa a possibilidade da razão subalterna para colocar-se em primeiro plano, em um diálogo "transepistemológico", ou seja, a posição epistêmica subalterna vis-à-vis à hegemonia epistêmica (MIGNOLO, 2011).
} 
e de cada etnia para dar sentido e tornar possível a discussão da diferença no cotidiano escolar continua a desafiar o trabalho pedagógico.

\section{O racismo na escola: não é bullying nem brincadeira de criança}

Mesmo com a existência das políticas educacionais afirmativas que trouxeram mudanças significativas ao currículo escolar o racismo de forma equivocada ou intencional tem sido diluído na discussão sobre o bullyingescolar. Apesar de relevante a coibição desse fenômeno, ao ser deslocado no contexto das agressões físicas, verbais e psicológicas, os casos de racismo são ignorados pelos professores. Ressalta-se que vários legisladores municipais pelo país propuseram projetos que visam evitar o bullyingescolar, apoiados pela mídia que divulga amplamente o seu significado e consequências, enquanto a implementação das leis que alteraram o currículo com a inserção da História e Cultura Africana e Afro-brasileira e as que punem o crime de racismo não são se quer mencionadas, mesmo quando algumas situações são caracterizadas em ambiente escolar.

Além de sofrer a discriminação racial, a criança negra ainda poderá ser ignorada e hostilizada pelos professores, em virtude de seu despreparo para lidar com a situação ou ainda pela naturalização da inferiorização racial. A crueldade, evidenciada como consequência disso, se torna ainda mais dolorosa quando se tem ciência que a criança negra passa grande parte de sua vida sendo apelidada de "macaca", "preto fedido", "sujo", "cabelo de assolam", "rolo de asfalto", entre outros tantos apelidos pejorativos, e ao relatar tais casos para os professores, na maioria das vezes é ignorada ou apenas escuta como resposta: "Isso é brincadeira, não liga". Por ser interpretada como errada, essa criança tende a não se manifestar e, por consequência, a família muitas vezes demora a entender que o filho está sendo vítima de injúrias raciais.

Assim, quando a criança negra está diante de uma cultura em que o bom está no branco, seu corpo, em primeiro lugar, está exposto àquilo que Costa (1984) chama de violência simbólica. Para esse autor:

Através da internalização compulsória e brutal de um ideal de Ego branco, é obrigado a formular para si um projeto identificatório incompatível com as propriedades biológicas do seu corpo. Entre o Ego e seu Ideal cria-se, então, um fosso que o sujeito negro tenta transpor, à custa de sua possibilidade de felicidade, quando não de seu equilíbrio psíquico. 
É dessa forma que o racismo toma configurações diversas no mundo psíquico do sujeito negro, no qual o ideal de brancura é incompatível com suas características, e o sujeito é identificado com valores e atributos tidos como negativos, já que são contrários ao ideal que circula socialmente.

As questões colocadas para os sujeitos negros, desde a infância é: como gostar do meu corpo se a imagem que reflito é negativa? Como construir uma imagem psíquica positiva em uma cultura que não me reflete, ao contrário, nega e anula a presença do meu corpo? Essas são algumas perguntas que podem traduzir um pequeno recorte sobre o drama de grande parte das crianças no Brasil, e nos leva a outro questionamento: se a cultura oferece apenas o que é incompatível com seu corpo e história, como o sujeito poderá amar, cuidar e sentir prazer com a imagem que tem de si?

Nesse raciocínio, é preciso seguindo a proposição de Costa (1984) e se atentar para a hipótese que:

O racismo esconde assim seu verdadeiro rosto. Pela repressão ou persuasão, leva o sujeito negro a desejar, invejar e projetar um futuro identificatório antagônico em relação à realidade de seu corpo e de sua história étnica e pessoal. Todo ideal identificatório do negro converte-se, desta maneira, num ideal de retorno ao passado, onde ele poderia ter sido branco, ou na projeção de um futuro, onde seu corpo e identidade negros deverão desaparecer. (COSTA, 1984, p. 5).

É nesse sentido que a idealização imposta pelo viés eurocêntrico é um fator que interfere de forma negativa na formação da identidade da criança negra ao impor um modelo a ser seguido e inferiorizar e negar toda a sua ancestralidade africana, seus traços fenótipos, cabelo e tom de pele.

\section{A educação das relações raciais: entre o prescrito e o vivido}

Com base no posicionamento apresentado e munidos das reflexões que acompanharam o processo de investigação, nesta seção apresentamos os dados finais da pesquisa e a análise de algumas entrevistas selecionadas. O grupo selecionado para participar da pesquisa foi composto por professores do primeiro ao nono ano do ensino fundamental, gestores escolares e coordenadores pedagógicos de 179 escolas públicas estaduais distribuídas em 63 municípios do estado de Mato Grosso do Sul no período de abril de 2013 a junho de 2015. Os participantes voluntários que responderam os questionamentos estão distribuídos nas funções 
de professor (76,4\%), Coordenador Pedagógico (14\%), Diretor de escola (47\%), Gerenciador Midiático (1\%) e Interprete de LIBRAS (0,3\%).

Estes participantes receberam um questionário com as seguintes indagações abertas: 01 - Você considera que há preconceito e discriminação étnico-racial no Brasil?; 02 - Você já presenciou alguma situação de preconceito ou discriminação no ambiente escolar?; 03 - Você tem conhecimento sobre a Educação das Relações étnico-raciais?; 04 - Você considera que o Brasil é um país sem discriminação sociocultural e étnico-racial?; 05 - Você considera a temática da diversidade étnico-racial necessária no currículo escolar?; 06 - Existem na escola situações em que envolvem relatos de preconceito e discriminação contra alunos, professores ou demais funcionários devido à cor de sua pele?; 07 - Você considera que a escola trata adequadamente as relações referentes a diversidade étnico-racial?; 08 - Você considera importante a data do dia 20 de novembro?; 09 - Você conhece as Leis Federais 10.639/2003 e 11.645/2008?; 10 - Na sua opinião, a Lei 10.639/2003 e 11.645/2008 são efetivamente implementadas em sua escola?; 11 - Qual é sua auto declaração, do ponto de vista étnicoracial?

A metodologia adotada na pesquisa é a quanti-qualitativa, pois se entende que a relação entre os dados quantitativos encontrados em similares respostas e sua discussão com base no teor reflexivo dessas respostar, proporciona uma maior da realidade investigada.

Para tanto separamos dois momentos para a pesquisa. Primeiro, a seleção do público alvo a receber o questionário, elencado acima, sua aplicação e coleta. Na sequência, já em posse dos 572 formulários selecionados com resposta para todos os questionamentos, tabulamos os dados de forma a nos possibilitar sua análise qualitativa, como explicitada a seguir.

Com relação a Questão 01, 83,5\% dos respondentes afirmam que o Brasil é palco de preconceito e discriminação étnico-racial e sociocultural, enquanto 5,6\% declararam não terem opinião formada sobre isso. As respostas que fundamentaram o posicionamento são marcadas por frases como:

Racismo não existe, porque o racismo comentado é para as pessoas de cor negra, índio, japonês e afinal o branco é quem sofre com o racismo, para mim é o que está sendo mais discriminado. (Entrevistado, 2014).

Raça, cor, não existe. $\mathrm{O}$ que existe são pessoas que se acham diferentes no ponto de vista intelectual e também no ponto de vista financeiro, ninguém é incapaz para não conseguir o que quer. (Entrevistado, 2014). 
Na sociedade atual é uma questão que não deveria ser mais discutido, pois já foi debatido várias vezes, eu não tenho preconceito. (Entrevistado, 2014).

O racismo não deveria existir, porque os negros e os índios são pessoas de uma cultura peculiar, inteligentes e amáveis quando compreendidos. De um convívio normal na sociedade de maioria brancos. Não os vejo diferentes apenas pela cor de pele. (Entrevistado, 2014).

Diante desses depoimentos percebemos que dificilmente esses professores conseguirão romper com o silenciamento e a ocultação de práticas discriminatórias e preconceituosas ainda presentes no ambiente escolar, por negarem a existência do racismo. Esta característica é, segundo Gomes (2012), consequência da própria execução da lei:

Esses dispositivos legais entram em confronto direto com o imaginário e as práticas de racismo e com o mito da democracia racial extremamente arraigados no bojo do processo de escolarização e no imaginário de profissionais da educação em todos os níveis da educação brasileira. Esse contexto produz subjetividade, interfere na construção das identidades e autoestima dos sujeitos negros, brancos, indígenas e outros. (GOMES, 2012, p. 24).

Por isso é preciso vencer alguns obstáculos relacionados à obediência epistêmica de matriz colonial, como a crença no mito da democracia racial, que negam a existência de racismo no Brasil e silencia situações de preconceito e discriminação no espaço escolar por acreditar que todos os brasileiros vivem em perfeita harmonia no que se refere a igualdade étnica.

Cabe ressaltar, é claro, que nem todas as respostas dos entrevistados revelaram o mesmo teor, a maioria definiu o conceito de racismo e pontuou de forma objetiva os malefícios da prática em si.

O preconceito racial é um tipo de preconceito infundado, retrógrado, irracional e idiota. Em meu ponto de vista, em nosso País, de dimensões continentais, onde há uma miscigenação generalizada, não deveria existir o preconceito racial, mas, infelizmente, existe. (Entrevistado, 2014).

Está previsto na Carta Magna do país que todos são iguais perante a lei e que não deve haver distinções de raça, cor, credo religioso, etc. Portanto não devemos jamais sermos preconceituosos com relação a cor da pele, a classe social ou a etnia. É sabido que negros, índios e pobres ainda são discriminados em nosso país. Mas é preciso reverter essa situação. (Entrevistado, 2014).

Contudo uma minoria indiferente pode com certeza influenciar negativamente na formação de crianças negras e brancas, pois considerando uma sala de aula com 40 (quarenta) 
alunos, temos 40 futuros cidadãos que poderão legitimar em suas ações a prática do racismo e ainda reproduzir a ideologia de superioridade racial.

No que tange à percepção da discriminação racial no espaço escolar, o total de $39 \%$ dos entrevistados afirmou não ter presenciado situações de preconceito ou discriminação contra $61 \%$ que responderam já ter presenciado alguma situação envolvendo preconceito ou discriminação racial. É instigante saber que há profissionais que nunca presenciado nenhum tipo de atitude discriminatória ou preconceituosa, mas a resposta que segue nos leva a uma percepção não muito positiva:

Na nossa escola compartilhamos de um ambiente muito agradável, onde diferenças não existem e eu como educadora e mediadora de conhecimentos tenho uma excelente relação com os alunos e com os meus companheiros de trabalho sem nenhum preconceito, seja, racial, social etc. (Entrevistado, 2014) (grifos nossos).

Negar a diferença é colaborar com o processo histórico de negação do racismo e naturalizar as desigualdades. No livro "Ciladas das diferenças", Pierucci, (1999, p. 7) sinaliza alguns aspectos significativos que tencionam o deslocamento epistêmico homogeneizado:

Somos todos iguais ou somos todos diferentes? Queremos ser iguais ou queremos ser diferentes? Houve um tempo que a resposta se abrigava segura de si no primeiro termo da disjuntiva. Já faz um quarto de século, porém, que a resposta se deslocou. A começar da segunda metade dos anos 70, passamos a nos ver envoltos numa atmosfera cultural e ideológica inteiramente nova, na qual parece generalizar-se, em ritmo acelerado e perturbador, a consciência de que nós, os humanos, somos diferentes de fato [...], mas somos também diferentes de direito. É o chamado "direito à diferença", o direito à diferença cultural, o direito de ser, sendo diferente. The righttobedifferent!, como se diz em inglês, o direito à diferença. Não queremos mais a igualdade, parece. Ou a queremos menos, motiva-nos muito mais, em nossa conduta, em nossas expectativas de futuro e projetos de vida compartilhada, o direito de sermos pessoal e coletivamente diferentes uns dos outros.

Esse deslocamento não implica negar a igualdade, mas afirmar a diferença, evidenciar o direito de "ser diferente". Nas situações que os professores identificaram atitudes de discriminação contra a criança negra, a cor da pele foi apontada por $34 \%$ dos profissionais entrevistados, o que enfatiza as contribuições dos estudos de Oracy Nogueira ao elucidar aspectos do preconceito no Brasil:

[...] como preconceito racial uma disposição (ou atitude) desfavorável, culturalmente condicionada, em relação aos membros de uma população, aos quais se tem como estigmatizados, seja devido à aparência seja devido a toda ou parte da ascendência étnica que lhes atribui ou reconhece. Quando o 
preconceito de raça se exerce em relação à aparência, isto é, quando toma por pretexto para as suas manifestações, os traços físicos do indivíduo, a fisionomia, os gestos, o sotaque, diz-se que é de marca; quando basta a suposição de que o indivíduo descende de certo grupo étnico, para que sofra as consequências do preconceito diz-se que é de origem. (NOGUEIRA, 1985, p. 79).

O preconceito, tal qual se apresenta no Brasil, é então designado por Nogueira (1985), por preconceito de marca, reservando-se para a modalidade em que ocorre nos Estados Unidos a designação de preconceito de origem. Entre o preconceito racial de marca e o preconceito racial de origem, o autor apontou as seguintes diferenças:

Quanto ao modo de atuar: o preconceito de marcas determina uma preterição: o de origem, uma exclusão incondicional dos membros do grupo atingido, em relação a situações ou recursos pelos quais venham a competir com os membros do grupo discriminador. [...] quanto à definição de membro do grupo discriminador e do grupo discriminado: onde o preconceito é de marca, serve de critério o fenótipo ou aparência racial; onde é de origem, presume-se que o mestiço, seja qual for sua aparência e qualquer que seja a proporção de ascendência do grupo discriminador ou do grupo discriminado, que se possa invocar, tenha as 'potencialidades hereditárias' deste último grupo e, portanto, a ele se filie, 'racialmente'. (NOGUEIRA, 1985, p. 79).

Apesar do IBGE adotar no critério de auto declaração a cor/raça amarela, branca, indígena, pretos e pardos, convivemos nas relações sociais com uma "palheta de cor”, na qual equivocadamente, na sociedade brasileira nega-se a cor preta e parda, ao elegerem outras cores, entre as quais: morena, mulata, cor de jambo, marrom bombom (MAIER, 2006). O racismo cordial está estampado nas atitudes daqueles que negam a existência do preconceito e, consequentemente refugiam-se no discurso da dificuldade de identificar quem é negro no Brasil.

$\mathrm{Na}$ escola a situação torna-se mais complexa quando o professor despreparado pede para as crianças utilizarem nas atividades o famigerado "lápis cor de pele", lápis com uma tonalidade rosa pêssego. Essa atitude, entendida por muitos como inocente, fortalece a afirmativa de que a criança negra é educada num ambiente que invisibiliza a sua presença negra, com as suas características fenotípicas, e muitas vezes ao tentar igualar, como no caso do "lápis cor-de-pele", perde-se a oportunidade de afirmar a identidade e educar na diferença.

Sobre a temática étnico-racial e a escola, $62 \%$ dos profissionais disseram ter conhecimentos sobre a educação e as relações étnico-raciais e $92 \%$ consideram necessária a inclusão e discussão da temática no currículo escolar, conforme observamos na percepção de um dos entrevistados: 
Os alunos precisam ser preparados para aceitar as diversidades étnico-racial, somente assim serão capazes de respeitar uns aos outros. O professor deve promover momentos de reflexão e conhecimento étnico-racial através de debates contextualizados. (Entrevistado E, 2014).

Dos 572 entrevistados, $4 \%$ responderam não conhecer a temática e estes mesmos $4 \%$ afirmaram não considerar importante discutir relações étnico-raciais em sala. Número pequeno, mas significativo, se considerarmos que os participantes se tratam de profissionais da educação pública estadual de uma unidade federativa onde a população não branca, considerada neste texto apenas como a população autodeclarada indígena, preta e parda, chega a 52\% (IBGE, 2010) do seu total, e onde o processo de colonização orientada a partir da década de 1940 foi quem lhe proporcionou a construção de sua identidade cultural, esta derivada de fluências nordestinas, sulistas, nortistas, italianas, japonesas, libanesas, entre outras.

Em relação ao tratamento da escola de um modo em geral sobre as legislações, 79\% dos entrevistados consideram que a escola aborda adequadamente a educação para as relações étnico-raciais, ao possibilitar a realização de palestras sobre a temática na escola, bem como a manutenção de materiais de consulta para a prática de leituras complementares por parte dos alunos, e atividades extracurriculares. Um total de $10 \%$ dos entrevistados informou que não consideram satisfatório o tratamento dado pela escola para com a temática, essa passando muitas vezes despercebida junto as demais “obrigações do currículo" (Entrevistado, 2014).

O questionamento relacionado à comemoração do dia 20 de novembro, introduzido na LDBEN pelo artigo Art.79-B, trouxe que 92\% dos entrevistados o consideram fundamental para o debate acerca das relações raciais no Brasil por expor o símbolo da resistência de todo um povo. Apenas $3 \%$ das respostas foram contrárias a essa afirmação e isso nos levou a pensar sobre como é possível que ainda existam profissionais que são avessos ao reconhecimento de sua história, pois independente do seu pertencimento étnico-racial, a história da resistência do povo escravizado no Brasil retrata um processo de construção do que hoje chamamos de nação brasileira. Negar a existência de qualquer tipo de resistência imposta pelo colonialismo é negar a história de uma nação.

Ao questionarmos sobre o conhecimento e o desempenho da escola para com a sua execução das Leis $n^{\circ} 10.639 / 2003$, o total de $57 \%$ de entrevistados conhece a finalidade da lei e 59\% disseram que a mesma está sendo implementada no currículo escolar de forma satisfatória. Destes, 34\% desconhecem a legislação e o que ela preconiza enquanto e 36,3\% 
citam que a escola trabalha a temática de forma parcial, apenas nas datas específicas, como o 20 de novembro, sem nenhuma outra ação no que se refere a diversidade.

Em uma das respostas, é identificada a ação da escola de forma fragmentada, refletindo que a ação, mais de dez anos após a promulgação da Lei $n^{\circ}$ 10.639/2003, ainda não está inserida na Proposta Pedagógica da escola.

A única vez que a escola fala alguma coisa sobre a população negra é no segundo semestre, quando é montado um painel com cartazes sobre a consciência negra, mas mesmo assim toda vez só é colocado fotos do negro sendo escravizado, não tem nada sobre o povo negro além deles como escravos. (Entrevistado, 2014).

O que percebemos ao cruzarmos as repostas e os debates com os professores é a presença de práticas isoladas, seja na forma de "currículo turístico" ou no 'Dia D", conforme alerta Santomé (2003), quando a escola ao discutir as questões da diversidade e da marginalização das culturas negadas no currículo escolar, tratam isoladamente, sob forma de lições ou unidades didáticas. Não se pode reservar apenas um dia de luta contra os preconceitos racistas, esta ação deve ser adotada diariamente, refletida na prática cotidiana.

$\mathrm{Na}$ décima primeira pergunta, "Qual é sua autodefinição, do ponto de vista étnicoracial? ", nos chamou atenção os diversos formatos das repostas, pois diferentemente do que esperávamos, apenas as categorias oficiais adotadas para definição étnico-racial, foram utilizadas justificativas sobre o seu pertencimento, conforme alguns exemplos que seguem:

Sou branca. A minha descendência por parte materna provém do ramo étnico português com ascendência judia portuguesa enquanto a paterna procede do ramo português com traços indígenas e árabe. (Entrevistado, 2014)

Não costumo me definir e não gosto de utilizar definições quanto a este assunto, por acreditar serem muito limitantes, entretanto, quando isso se faz necessário, me defino como Pardo pela miscigenação que ocorreu em minha família. (Entrevistado, 2014)

Sou afrodescendente, meu pai é filho de negro brasileiro com branca filha de alemão e minha mãe é filha de negro brasileiro com índia, portanto sou morena com cabelos encaracolados. (Entrevistado, 2014)

A explicação que segue a autodeclaração evidencia a necessidade do profissional em um fortalecimento identitário. Este fator é observado de forma positiva ao passo que permite a esses profissionais da educação articular maneiras de contribuir com a formação da identidade dos seus alunos, pois valorizar-se enquanto parte de um grupo étnico específico é fundamental para o reconhecimento deste, e isso só ocorre a partir da autoidentificação de cor/raça. 
Neste viés, ao discutir o papel da escola e dos educadores, Giroux (2003, p. 88) considera que:

\begin{abstract}
Os educadores não poderão ignorar, no próximo século, as difíceis questões do multiculturalismo, da raça, da identidade, do poder, do conhecimento, da ética e do trabalho que, na verdade, as escolas já estão tendo de enfrentar. Essas questões exercem um papel importante na definição do significado e do propósito da escolarização, do que significa ensinar e da forma como os/as estudantes devem ser ensinados/ensinadas para viver em um mundo que será amplamente mais globalizado, high tech e racialmente diverso que em qualquer outra época da história.
\end{abstract}

A escola, por ser um espaço privilegiado para a formação de indivíduos, pode produzir os discursos que promovem a exclusão ou enfrentar o desafio de desenvolver ações culturais e políticas capazes de transformar os indivíduos, as relações sociais e o racismo, visando à construção de uma sociedade mais igualitária. Para Santos (2001, p. 106), “[...] a escola pode garantir e promover o conhecimento de si mesmo, no encontro com o diferente, pois é conhecendo o outro, que questiono o meu modo de ser, coloco em discussão os meus valores, dialogo".

A identidade da criança negra deve ser alicerçada quando ela ingressa na escola, ou seja, desde a pré-escola, e isso ocorrerá quando a escola e educadores compreenderem que os alunos são indivíduos pertencentes a culturas diferentes, que são diferentes, mas não desiguais, e que a compreensão e o respeito à diferença são condutas indispensáveis.

Para isso, é fundamental a compreensão de que racismo e a discriminação são uma construção social, ideologicamente construída ao longo da história. Assim, se foi construída, podem ser desconstruídas, e essa tarefa não é apenas da escola, mas de toda a sociedade, no sentido de colocar sob rasura a ideologia do embranquecimento, combater o racismo e afirmar a identidade negra.

\title{
Considerações Finais
}

A violência racista pode submeter o sujeito negro a uma situação cuja desumanidade nos desarma e deixa perplexos. Seria difícil encontrar o adjetivo adequado para nomear esta odiosa forma de opressão. (COSTA, 1984).

A análise das falas dos professores permite-nos afirmar que mesmo superficialmente há um conhecimento sobre o que preconiza as leis, mas há também muita dificuldade em trabalhar em suas práticas pedagógicas, pois os entrevistados reconhecem que sabem pouco 
sobre a cultura e história dos povos africanos. Ou seja, ainda há nas escolas investigadas práticas pedagógicas homogeneizantes e etnocêntricas, que, silenciosamente, impõem a cultura colonizadora, os valores e ideologias etnocêntricas. Diante do exposto, uma pergunta requer resposta: Como a criança negra pode construir ou fortalecer sua identidade em uma cultura em que o ideal predominante é o branco?

O que percebemos é uma perpetuação do significado de diferença como algo ruim, onde a alteridade é utilizada como limitadora do acesso à liberdade individual, expressa subjetivamente através de posturas que permitem a prática do racismo e da discriminação étnico-racial em instituições nas quais seus profissionais deveriam ser capacitados para atuar de forma responsável e consciente para com a diversidade, seja ela étnica, cultural ou de gênero.

Não adianta as Leis n 10.639/2003 e n 11.645/2008 obrigar a inserção do conteúdo no currículo, e os livros trazerem uma bagagem de conteúdo, se os professores não estão aptos a trabalharem isso em sala. $\mathrm{O}$ que percebemos é um voto de silêncio para com as deficiências na formação docente, estando o professor amparado pelos preconceitos e tabus comuns à sociedade. Quando um profissional da saúde se recusa a atender um paciente devido a sua cor de pele, o caso se torna conhecimento de todos, mas quando um professor pratica ou permite a prática do preconceito racial ou étnico no ambiente escolar, pouca se divulga, até mesmo dentro da escola, por ser aceito como algo "normal".

Pode parecer extremista utilizar este exemplo, mas um profissional que insiste em defender a inexistência do racismo, que declara serem as pessoas negras "mais preguiçosas" que os demais, que os indígenas têm "menos afinidade ao trabalho", que o "descobrimento do Brasil" serviu para trazer a civilização para os índios, dentre outras defesas, contribui sim para a perpetuação de formas de preconceito étnico-racial.

O que podemos dizer a partir desta investigação é que as escolas sul-mato-grossenses estão no caminho certo no que se refere ao trabalho minimizador do racismo na escola, possibilitando debates e trabalhos pedagógicos que contribuem para a formação da identidade social da criança e levando-as a enxergar seu grupo de pertencimento com outros olhos, estes mais livres das lentes do preconceito e discriminação.

Mas isso não é o suficiente. É indiscutível a necessidade de se desenvolver trabalhos mais incisivos nas escolas, principalmente para com a capacitação profissional dos professores, no que se refere a temática preconceito racial. O número de profissionais que optaram por responder "parcialmente"; "sem opinião formada"; "não me interesso pela 
temática" nos levou a questionar sobre como estão sendo realizadas as aulas da temática étnico-racial por estes profissionais.

A legislação foi o começo de uma luta que se desenvolve diariamente através de processos democráticos que são construídos paulatinamente nas escolas e que levaram para toda a sociedade uma nova postura no que diz respeito aos grupos discriminados. Mas é importante frisar que a Lei orienta a ação, mas o produto final é realizado pelo profissional da educação. Somente quando tivermos uma conscientização integral por meio dos profissionais da educação sobre as formas de preconceitos e discriminação racial teremos a possibilidade de minimizar, e a longo prazo, extinguir tais práticas.

\section{REFERÊNCIAS}

BACKES, José Licínio. O acesso das classes populares à universidade: implicações para a construção de sua identidade cultural. 29ª Reunião Anual da ANPED, Caxambu, 2006.

BRASIL. Constituição da República Federativa do Brasil. Brasília, DF: Senado 1988.

BRASIL. Diretrizes Curriculares Nacionais para a Educação das relações Étnico Raciais e para o Ensino de História e Cultura Afro-Brasileira e Africana. Secretaria Especial de Políticas de Promoção da Igualdade Racial. Brasília: MEC, 2004.

BRASIL. Lei n⿳ 10.639/2003. Diário Oficial da União de 10 de janeiro de 2003.

BRASIL. Lei no 11.645/2008. Diário Oficial da União de 10 de março de 2008.

BRASIL. Ministério da Educação. Plano nacional de implementação das diretrizes curriculares nacionais para educação étnico-raciais e para o ensino de história e cultura afro-brasileira e africana. Brasília: MEC, 2004.

BRASIL. Orientações e ações para a educação das relações étnico-raciais. Coleção Educação para Todos, Brasília, 2006.

BRASIL. Senado Federal. Lei de Diretrizes e Bases da Educação Nacional: nº 9.394/1996. Brasília: 1996.

CANDAU, Vera M. F. (org.). Sociedade, Educação e Cultura(s). Questões e propostas. Petrópolis: Vozes, 2002.

CANEN, Ana. Formação de professores: diálogo das diferenças. Ensaio: Avaliação e Políticas Públicas em Educação. Rio de Janeiro, v. 5, n. 17, p. 477-94, out.-nov. 2003. 
COSTA, Jurandir Freire. Da cor ao corpo: a violência do racismo. In: SOUZA, Neusa Santos. Tornar-se negro. As vicissitudes da identidade do negro brasileiro em ascensão social. Rio de Janeiro: Graal, 1984.

GIROUX, Henry. Atos impuros. A prática política dos estudos culturais. Tradução de: COSTA, Ronaldo. Porto Alegre: Artmed, 2003.

GOMES, Nilma Lino. Corpo e cabelo como ícones de construção da beleza e da identidade negra nos salões étnicos de Belo Horizonte. Belo Horizonte: UFMG: 2002.

GOMES, Nilma Lino. Práticas pedagógicas de trabalho com relações étnico-raciais na escola na perspectiva da Lei no 10.639/03. 1. ed. Brasília: MEC ; Unesco, 2012.

IBGE. Censo Demográfico 2010: Características gerais da população. Rio de Janeiro: IBGE, 2012

MAIER, Félix. Racismo cordial: qual é a sua cor predileta? Disponível em http://www.midiasemmascara.org/arquivos/5687-racismo-cordial-qual-e-a-sua-corpredileta.html, Acesso em 28 de jan. de 2016.

MARQUES, Eugenia Portela de Siqueira. Políticas Curriculares Nacionais E Práticas Pedagógicas: Possibilidades abertas pela Lei ${ }^{\circ} 10.639 / 2003$ para o estudo das relações étnico - raciais na escola. XVI ENDIPE - Encontro Nacional de Didática e Práticas de Ensino UNICAMP: Campinas, 2012.

MIGNOLO, Walter D. Novas reflexões sobre "Ideia da América Latina": a direita, a esquerda e a opção descolonial. Caderno CRH, v.21, n.53, 2008.

MIGNOLO, Walter D. The darker side of Western modernity. Durham: Duke University Press, 2011.

MUNANGA, Kabengele (org.). Estratégias e políticas de combate à discriminação racial. São Paulo: EdUSP, 1996.

NOGUEIRA, Oracy. Preconceito racial de marca e preconceito racial de origem - sugestão de um quadro de referência para a interpretação do material sobre relações raciais no Brasil. In NOGUEIRA, Oracy(org.). Tanto preto quanto branco: estudos de relações raciais. São Paulo: T.A. Queiroz, 1985.

OLIVEIRA, Zilma de Moraes R. Interações sociais e desenvolvimento: A perspectiva sociohistórica. Caderno do CEDES, 20, 2000.

PIERUCCI, Antônio Flávio. Ciladas da diferença. São Paulo: Ed. 34, 1999.

PINTO, ReginaPahim. O Movimento negro em São Paulo: luta e identidade. São Paulo, 1993.

REDAÇÃO PRAGMATISMO. O desabafo de um menino de 11 anos que é vítima de racismo na escola. Disponível em <http://www.pragmatismopolitico.com.br/2015/08/o- 
desabafo-de-um-menino-de-11-anos-que-e-vitima-de-racismo-na-escola.html.. Acesso em 27 de janeiro de 2016.

ROSEMBERG, Fúlvia. Expansão da educação infantil e processos de exclusão. Cadernos de Pesquisa, São Paulo, n. 107, p. 7-40, jul. 1999.

SANTOMÉ, Jurjo Torres. A educação em tempos de neoliberalismo. Porto Alegre: Artes Médicas, 2003.

SANTOS, Isabel Aparecida. A responsabilidade da escola na eliminação do preconceito racial: alguns caminhos. In: CAVALLEIRO, Eliane (org.) Racismo e anti-racismo na educação - repensando nossa escola. São Paulo: Summus, 2001.

SILVA, Petronilha Beatriz G. Quebrando o silêncio: resistência de professores negros ao racismo. In: SERBINO, R. V., GRANDE, M. A. R. L. A Escola e seus alunos: estudos sobre diversidade cultural. São Paulo: UNESP, 1995.

SILVA, Petronilha Beatriz G.; BARBOSA, Lucia Maria de Assunção (orgs.). O pensamento negro em educação no Brasil: expressões disciplina movimento negro. São Carlos: Ed. da UFSCar, p.17-30, 1997.

SISS, Ahyas. Afro-brasileiros, cotas e ação afirmativa: razões históricas. Rio de Janeiro: Quartet, Niterói: PENESB, 2003.

WALSH, Catherine. Interculturalidade Crítica e Pedagogia Decolonial: in-surgir, re-existir e re-viver. In: CANDAU, Vera Maria. (Org.). Educação Intercultural na América Latina: entre concepções, tensões e propostas. Rio de Janeiro: 7 Letras, 2009.

\section{SOBRE OS AUTORES:}

\section{Eugenia Portela Siqueira Marques}

Doutora em Educação pela Universidade Federal de São Carlos (UFSCar); Universidade Federal do Mato Grosso do Sul - Brasil; Programa de Pós-Graduação em Educação; Grupo de Estudos e Pesquisas sobre Educação, Relações étnico-raciais e Formação de professores GEPRAFE. E-mail: portelaeugenia@gmail.com

(iD http://orcid.org/0000-0003-3182-171X

\section{Wilker Solidade da Silva}

Doutorando em Educação pela Universidade Federal do Paraná (UFPR); Programa de PósGraduação em Educação (PPGE/UFPR); Grupo de Estudos e Pesquisas sobre Educação, Relações étnico-raciais e Formação de professores - GEPRAFE; Núcleo de Estudos Afrobrasileiros da UFPR (NEAB/UFPR). E-mail: wilkersolidade@ gmail.com

(iD) http://orcid.org/0000-0002-5486-3130

Recebido em: 21 de novembro de 2019 Aprovado em: 28 de fevereiro de 2020

Publicado em: 01 de abril de 2020 